\title{
The Crystal Structure of Phosphorous Acid
}

\author{
SVEN FURBERG and PER LANDMARK \\ Chemical Institute, University of Bergen, Bergen, Norway
}

\begin{abstract}
The crystal structure of phosphorous acid, $\mathrm{H}_{3} \mathrm{PO}_{3}$, has been determined by X-ray methods. The space group is Pna2, and there are eight molecules per unit cell. Two of the $\mathrm{P}-\mathrm{O}$ bonds in the molecule, presumably the $\mathrm{P}-\mathrm{OH}$ bonds, are found to be about $1.54 \AA$, whereas the bond to the third oxygen atom is significantly shorter, 1.47 $\AA$. There are two hydrogen bonds for each molecule. These observations are in agreement with the accepted structural formula $\mathrm{H}_{2}\left(\mathrm{HPO}_{3}\right)$.
\end{abstract}

A phosphorous acid, $\mathrm{H}_{3} \mathrm{PO}_{3}$, is dibasic, it is generally assumed that one of
the hydrogen atoms is linked directly to the phosphorus atom. In connect-
ion with our work on phosphoric acid ${ }^{2}$ we thought it of value to study the
structure of this interesting molecule by X-ray crystallographic methods,
especially as no such investigation of phosphites was reported in the literature.
Only very recently the first crystal structure determination of a phosphite,
$\mathrm{MgHPO}_{3} \cdot 6 \mathrm{H}_{2} \mathrm{O}$, was published ${ }^{1}$, showing $\mathrm{HPO}_{3}{ }^{-}$ions with trigonal symmetry.

\section{[EXPERIMENTAL}

Phosphorous acid was prepared by hydrolysis of phosphorus trichloride and recrystallized from water and alcohol. The best crystals were obtained from the latter solvent. Mp. $73^{\circ} \mathrm{C}$ (uncorr.). The crystals are hygroscopic and were kept in thinwalled glass capillaries during the exposures. Weissenberg and oscillation diagrams were taken about the $a$ - and $c$-axes using $\mathrm{Cu} K a$ radiation $(\lambda=1.542 \AA)$. The intensities were estimated visually, and corrected for Lorentz and polarization effects. Very small crystals with even cross-sections were used and no correction for absorption was made.

\section{CRYSTAL DATA}

The crystals are orthorrombic, generally elongated along $a$, with unit cell dimensions $a=7.27 \AA, b=12.06 \AA$ and $c=6.85 \AA$. These values are probably accurate to within $0.5 \%$. By flotation in mixtures of carbon tetrachloride and ethylene dibromide a density of $1.806 \mathrm{~g} / \mathrm{cm}^{3}$ was found, corresponding to eight (calc. 7.96) molecules $\mathrm{H}_{3} \mathrm{PO}_{3}$ in the unit cell.

Acta Chem. Scand. 11 (1957) No. 9 

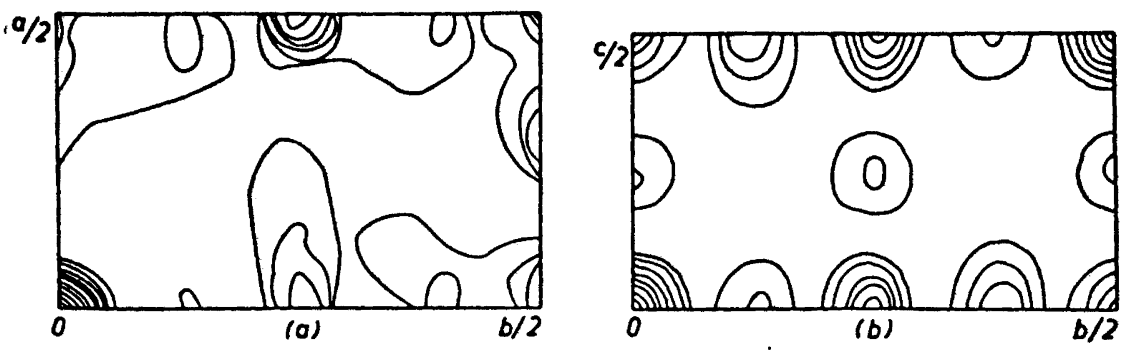

Fig. 1. Patterson projections on the (001) plane (a) and the (100) plane (b).

Systematic absences occur in the $0 k l$-reflections for $k+l$ odd and in the $h 0 l$-reflections for $h$ odd. The space groups $P n a 2_{1}$ and $P$ nam are both compatible with these observations. The crystals were tested for piezoelectric effects with a sensitive apparatus built by one of us (P.L.), but no effect was found. The space group Pna2 $2_{1}$ was nevertheless tentatively assumed on the basis of space considerations, and the subsequent structure analysis showed the choice to be correct. As this space group has four general positions, the asymmetric unit consists of two molecules $\mathrm{H}_{3} \mathrm{PO}_{3}$. Reflections $0 k 0$ are extremely weak when $k$ is not $4 \mathrm{n}$, and the crystals have in fact pseudotetragonal symmetry.

\section{THE STRUCTURE DETERMINATION}

Projections of the structure along the $c$ and $a$ axes were determined by Patterson, $F$ and $\left(F_{\mathrm{o}}-F_{\mathrm{c}}\right)$ syntheses. The $c$ projection was tackled first as it is the only one with apparent centres of symmetry.

The c-projection. The Patterson synthesis reproduced in Fig. la indicates that one phosphorus atom lies at $y=1 / 8$ and the other at $y=3 / 8$, and that approximately $x=0$ for one or both of them. Coordinates $(0,1 / 8)$ ard $(0,3 / 8)$ were chosen for the first Fourier synthesis, from which some information on the positions of the oxygen atoms was cbtained. Because of the pseudotetragonal symmetry a difference of $b / 4$ in the $y$ coordinates of correspor ding atoms in the two crystallographically independent molecules was assumed. Some agreement between $F_{\mathrm{o}}$ and $F_{\mathrm{c}}$ was obtained by Fourier refinement. However, the value of $F_{c}$ remained very small for some strong reflections. The likely signs of these were then derived by the "multiplication rule" (Sayre ${ }^{3}$ ). The corresponding Fourier map indicated clearly radical shifts in the $x$ coordinates of some of the oxygen atoms, and by further refinement the final electron density map given in Fig. 2a was obtained. Four further refinements of the atomic coordinates were carried out by $\left(F_{0}-F_{c}\right)$ synthesis. The same temperature factor $\exp \left(-2.2 \sin ^{2} \Theta / \lambda^{2}\right)$ was used for all the atoms, although the finaldifference map shows this to be only approximately correct. The atomic scattering factors employed are those given by Viervoll and Øgrim 4 . No attempt was made to derive the positions of the hydrogen atoms from the difference maps, and their contribution to the structure factors was calculated from assumed positions. The final value of the reliability index $R=\left(\Sigma\left|F_{\mathrm{o}}-F_{\mathrm{c}}\right|\right) / \Sigma\left|F_{\mathrm{o}}\right|$ is 

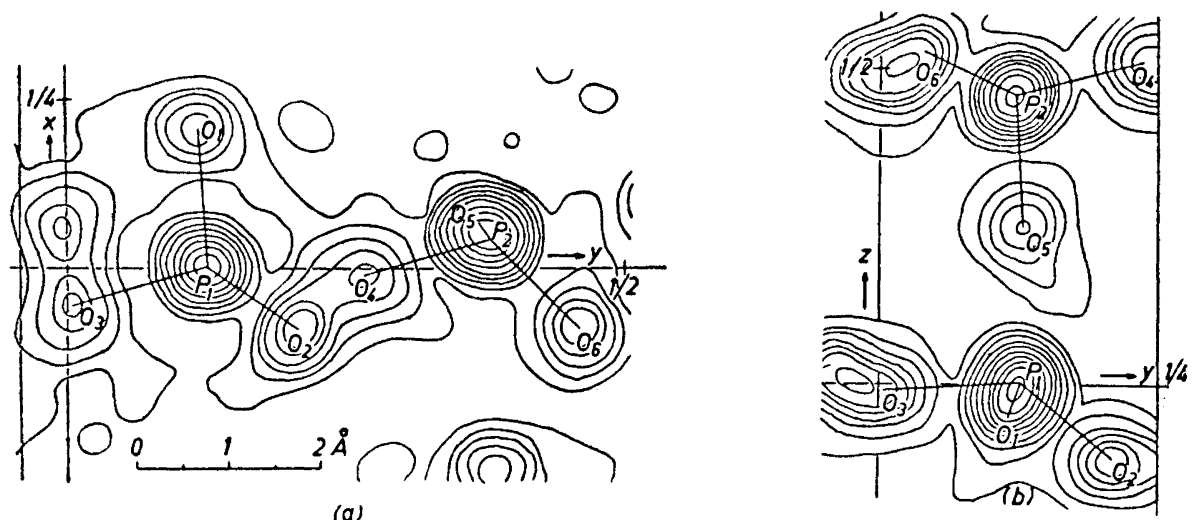

Fig. 2. Electron density projections on the (001) plane (a) and the (100) plane (b). Contours at $2,4,6, \ldots \theta . \AA^{-2}$, every second contour being omitted above 12 e. $\AA^{-2}$. Calculated at $1 / 60$ of $b$ and $1 / 30$ of $a$ and $c$.

0.10. The strongest reflection, 200 , which evidently suffers from extinction (as well as 002 in the $a$ projection), is not included in the calculation of $R$. Reflections not observed are only taken into account when $F_{\mathrm{c}}$ exceeds the observable limit.

The a-projection. The Patterson synthesis (Fig. lb) shows that the difference in $z$-coordinates of the two phosphorus atoms probably is near $c / 2$. Approximate $z$-coordinates for the oxygen atoms were derived from the known coordinates and the $\mathrm{P}-\mathrm{O}$ distances found in phosphoric acid ${ }^{2}$. Two different mutual orientations of the molecules were possible, which both gave $R=0.33$. The one chosen changed in the course of the refinement to the other possibility. Three Fourier refinements brought $R$ down to 0.20 , followed by five difference syntheses which made $R$ drop to 0.10 . As this projection is non-centrosymmetric, the atoms were in each refinement moved approximately twice the amount indicated by the Fourier- and difference-maps. The process would have been speedier if the atoms had been moved even more than this in each refinement. The final electron density map is shown in Fig. 2b, and the atomic coordinates are given in Table 1. The temperature factor is the same as in the $c$-projection. In Table 3 observed and calculated structure factors are given.

Table 1. Atomic coordinates as fractions of the corresponding cell edge.

$\begin{array}{cccc}\text { Atom } & x & y & z \\ \mathrm{P}_{1} & 0.002 & 0.1265 & 0.003 \\ \mathrm{P}_{2} & 0.046 & 0.378 & 0.461 \\ \mathrm{O}_{1} & 0.208 & 0.116 & 0.951 \\ \mathrm{O}_{2} & 0.910 & 0.209 & 0.874 \\ \mathrm{O}_{3} & \mathbf{0 . 9 4 0} & 0.004 & 0.985 \\ \mathrm{O}_{4} & \mathbf{0 . 9 9 4} & 0.259 & 0.518 \\ \mathrm{O}_{3} & 0.075 & 0.369 & 0.241 \\ \mathrm{O}_{6} & \mathbf{0 . 9 0 9} & \mathbf{0 . 4 5 9} & 0.518\end{array}$




\section{DESCRIPTION AND DISCUSSION OF THE STRUCTURE}

From the atomic coordinates in Table 1 the bond lengths and bond angles given in Table 2 were calculated.

Table 2. Bond lengths (in $\AA$ units) and bond angles.

\begin{tabular}{llll}
\multicolumn{2}{c}{ Molecule I } & \multicolumn{2}{c}{ Molecule II } \\
$\mathrm{P}_{1}-\mathrm{O}_{1}$ & 1.544 & $\mathrm{P}_{2}-\mathrm{O}_{3}$ & 1.526 \\
$\mathrm{P}_{1}-\mathrm{O}_{2}$ & 1.485 & $\mathrm{P}_{2}-\mathrm{O}_{6}$ & 1.451 \\
$\mathrm{P}_{1}-\mathrm{O}_{3}$ & 1.552 & $\mathrm{P}_{2}-\mathrm{O}_{4}$ & 1.535 \\
$\mathrm{O}_{1}-\mathrm{P}_{1}-\mathrm{O}_{3}$ & $111^{\circ}$ & $\mathrm{O}_{3}-\mathrm{P}_{2}-\mathrm{O}_{6}$ & $114^{\circ}$ \\
$\mathrm{O}_{1}-\mathrm{P}_{1}-\mathrm{O}_{3}$ & $101^{\circ}$ & $\mathrm{O}_{3}-\mathrm{P}_{2}-\mathrm{O}_{4}$ & $103^{\circ}$ \\
$\mathrm{O}_{2}-\mathrm{P}_{1}-\mathrm{O}_{3}$ & $117^{\circ}$ & $\mathrm{O}_{8}-\mathrm{P}_{8}-\mathrm{O}_{4}$ & $114^{\circ}$
\end{tabular}

The standard deviation of the atomic coordinates were estimated by applying the formula given by Cruickshank ${ }^{5}$. The following values were found: $\sigma(x)=0.004 \AA, \sigma(y)=0.003 \AA, \sigma(z)=0.005 \AA$ for the phosphorus atoms; $\sigma(x)=0.016 \AA, \sigma(y)=0.012 \AA, \sigma(z)=0.024 \AA$ for the oxygen atoms. In the case of $\sigma(z)$ the lack of a centre of symmetry is taken into account by multiplication by 2 . The standard deviation in the bond lengths vary between $0.013 \AA$ for the bond $\mathrm{P}_{1}-\mathrm{O}_{3}$ and $0.024 \AA$ for $\mathrm{P}_{2}-\mathrm{O}_{5}$. Unfortunately, an oxygen atom is very close to a phosphorus atom in each projection $\left(\mathrm{O}_{5}\right.$ and $\mathrm{O}_{1}$, respectively), and the error in the position of these atoms may be considerably greater than should be expected from the calculated standard deviations. This does not influence the bond lengths appreciably, but makes the values derived for the bond angles rather uncertain. The maximum error is estimated to about $5^{\circ}$ for the angles $\mathrm{O}_{1}-\mathrm{P}_{1}-\mathrm{O}_{2}$ and $\mathrm{O}_{5}-\mathrm{P}_{2}-\mathrm{O}_{6}$ and to about $3^{\circ}$ for the other angles.

It will be seen that the two crystallographically independent molecules are found to be identical within the limits of error. The differences observed in the bond angles may also partly be due to deformation by van der Waals forces ${ }^{6}$. In each of the molecules there is one shorter and two longer $\mathrm{P}-\mathrm{O}$ bonds, and one of the bond angles is considerably smaller than the others. The mean dimensions of the two molecules are given in Fig. 3. The short P-O bond, which presumably corresponds to the "lone" oxygen, has the length of 1.47 $\AA$, and is significantly shorter than the two bonds to the "hydroxyl" oxygens, for which values close to $1.54 \AA$ are found. The angle between the two $\mathrm{P}-\mathrm{OH}$ bonds is as small as $102^{\circ}$, whereas all the angles involving the short $\mathrm{P}-\mathrm{O}$ bond are greater than the tetrahedral angle, their mean value being $114^{\circ}$. The $\mathrm{O}-\mathrm{O}$ distance across the small angle is only $2.39 \AA$ in both molecules. Approximate positions for the hydrogen atoms of the hydroxyl groups may be derived from the directions of the hydrogen bonds. All O-H bonds lie roughly in the plane of the two $\mathrm{P}-\mathrm{OH}$ bonds, and the whole molecule has thus approximately a plane of symmetry. These molecular dimensions are, as might be expected, somewhat different from those reported for the phosphite ion, which is found to have threefold symmetry about the $\mathrm{P}-\mathrm{H}$ bond direction with $\mathrm{P}-\mathrm{O}$ bonds of length $1.51 \AA$ and $\mathrm{O}-\mathrm{P}-\mathrm{O}$ bond angles of $110^{\circ}$. 
Table 3. Observed and calculated structure factors. The values given are one quarter of the absolute values.

\begin{tabular}{|c|c|c|c|c|c|}
\hline$h k l$ & $F_{0}$ & $F_{\mathrm{c}}$ & $h k l$ & $F_{0}$ & $F_{\mathrm{c}}$ \\
\hline $\begin{array}{l}011 \\
031\end{array}$ & $\begin{array}{l}1.8 \\
8.8\end{array}$ & $\begin{array}{l}1.5 \\
6.5\end{array}$ & 0140 & $<0.8$ & $\begin{array}{l}+0.1 \\
0.9\end{array}$ \\
\hline $\begin{array}{l}051 \\
071\end{array}$ & $\begin{array}{r}12.2 \\
2.7\end{array}$ & 3.1 & 130 & 1.2 & $\begin{array}{l}+0.0 \\
+1.1\end{array}$ \\
\hline 091 & 3.9 & 3.9 & 140 & 6.0 & +5.5 \\
\hline 0111 & 2.2 & 2.3 & 150 & |7.1 & $\begin{array}{l}+7.3 \\
\end{array}$ \\
\hline 0131 & 2.3 & 2.1 & 160 & $<1.0$ & -0.2 \\
\hline 0151 & 1.2 & 1.5 & 170 & 1.3 & +1.5 \\
\hline 002 & 18.0 & 38.4 & 180 & 1.4 & -1.2 \\
\hline 022 & 5.8 & 6.4 & 190 & 2.8 & +2.1 \\
\hline 042 & 4.8 & 5.8 & 1100 & $<1.2$ & -0.6 \\
\hline 062 & 2.2 & 1.2 & 1110 & 2.6 & +3.0 \\
\hline 082 & 13.5 & 14.7 & 1120 & $<1.2$ & -0.6 \\
\hline 0102 & 3.6 & 3.4 & 1130 & 1.5 & +1.6 \\
\hline 0122 & 5.7 & 5.9 & 1140 & $<1.0$ & -0.4 \\
\hline 0142 & 1.5 & 1.3 & 1150 & 2.3 & +2.3 \\
\hline 013 & 8.1 & 8.3 & 200 & 16.8 & +34.6 \\
\hline 033 & 5.8 & 5.4 & 210 & 2.3 & -2.2 \\
\hline 053 & 8.3 & 8.4 & 220 & 2.7 & -2.7 \\
\hline 073 & 2.2 & 1.8 & 230 & 9.4 & -9.4 \\
\hline 093 & $<1.2$ & 0.3 & 240 & 4.6 & -4.8 \\
\hline 01113 & $<1.2$ & 0.3 & 250 & 10.6 & +11.0 \\
\hline 0133 & 1.3 & 0.7 & 260 & $<1.2$ & +0.7 \\
\hline 004 & 17.4 & 21.1 & 270 & 8.9 & +8.4 \\
\hline 024 & 4.9 & 5.1 & 280 & 12.8 & +12.9 \\
\hline 044 & 11.3 & 11.3 & 290 & 3.5 & -2.9 \\
\hline 064 & 1.8 & 0.9 & 2100 & $<1.2$ & -1.1 \\
\hline 084 & 11.8 & 12.5 & 2110 & $<2.1$ & -1.1 \\
\hline 0104 & 2.6 & 3.2 & 2120 & 5.4 & +5.3 \\
\hline 0124 & 4.6 & 4.2 & 2130 & $<1.0$ & +0.9 \\
\hline 015 & 4.2 & 4.5 & 310 & 3.7 & +1.8 \\
\hline 035 & 5.0 & 5.1 & 320 & 12.4 & +13.9 \\
\hline 055 & 7.4 & 8.1 & 330 & 3.7 & +2.7 \\
\hline 075 & 3.1 & 3.3 & 340 & 5.5 & -5.4 \\
\hline 095 & 1.4 & 1.9 & 350 & $<1.2$ & +1.3 \\
\hline 0115 & 2.4 & 2.5 & 360 & 8.7 & -8.5 \\
\hline 006 & 7.8 & 6.8 & 370 & 4.4 & +3.2 \\
\hline 026 & 2.9 & 2.8 & 380 & 4.3 & -3.5 \\
\hline 046 & 5.8 & 5.5 & 390 & $<1.2$ & -0.9 \\
\hline 066 & 1.1 & 0.7 & 3100 & 5.6 & +5.2 \\
\hline 086 & 5.3 & 4.9 & 3110 & $<1.2$ & -0.8 \\
\hline 0106 & 1.6 & 1.7 & 3120 & $<1.2$ & +0.9 \\
\hline 017 & 2.2 & 2.2 & 3130 & $<1.0$ & +0.4 \\
\hline 037 & 2.1 & 1.9 & 3140 & 2.6 & -2.5 \\
\hline 057 & 3.4 & 3.8 & 400 & 10.0 & +10.4 \\
\hline 077 & 1.8 & 1.8 & 400 & 10.0 & +10.4 \\
\hline 008 & 4.9 & 4.3 & 410 & 1.2 & -0.9 \\
\hline 028 & 1.1 & 1.0 & 420 & 3.3 & -3.0 \\
\hline 048 & 3.4 & 2.7 & 430 & 5.1 & -4.5 \\
\hline 020 & 0.6 & -0.5 & 440 & 9.4 & -8.5 \\
\hline 040 & 12.2 & -13.9 & 450 & 7.5 & +7.5 \\
\hline 060 & $<0.8$ & +0.4 & 460 & 2.5 & -2.1 \\
\hline 080 & 18.4 & +19.6 & 470 & 5.5 & +5.0 \\
\hline 0100 & 1.2 & -1.6 & 480 & 9.8 & +9.6 \\
\hline 0120 & 8.9 & -9.3 & 490 & 2.2 & -2.7 \\
\hline
\end{tabular}

Acta Chem. Scand. 11 (1957) No. 9 
Table 3. Continued.

\begin{tabular}{|c|c|c|c|c|c|}
\hline$h k l$ & $F_{0}$ & $F_{\mathrm{c}}$ & $h k l$ & $F_{0}$ & $F_{\mathrm{c}}$ \\
\hline 4100 & $<1.2$ & -0.6 & 660 & 1.6 & -1.9 \\
\hline 4110 & $<1.2$ & -0.7 & 670 & 3.7 & \\
\hline 4120 & 2.9 & -2.0 & 680 & 3.4 & $\begin{array}{r}+3.3 \\
+\end{array}$ \\
\hline 4130 & 1.6 & +1.5 & 690 & 1.9 & \\
\hline 510 & 7.3 & +7.6 & 6100 & 1.1 & -1.3 \\
\hline 520 & 6.0 & +6.8 & 6110 & 2.8 & -3.1 \\
\hline 530 & 3.7 & -3.0 & 710 & 3.2 & $\begin{array}{r}+3.2 \\
\end{array}$ \\
\hline 540 & $<1.2$ & -0.7 & 720 & 3.3 & +2.7 \\
\hline 550 & 7.4 & -7.3 & 730 & 3.7 & -3.7 \\
\hline 560 & 5.1 & -5.1 & 740 & 1.9 & +1.9 \\
\hline 570 & 6.3 & +5.7 & 750 & 3.8 & $\begin{array}{l}T \\
-4.7\end{array}$ \\
\hline 580 & $<1.2$ & -0.5 & 760 & 2.4 & -2.1 \\
\hline 590 & 1.8 & +0.8 & 770 & 2.9 & $+\mathbf{3 . 5}$ \\
\hline 5100 & 3.6 & +3.6 & 780 & 0.9 & +1.0 \\
\hline 5110 & 3.2 & -3.1 & 790 & 0.9 & +0.1 \\
\hline 5120 & $<1.0$ & +0.5 & 800 & $<1.0$ & $\begin{array}{l}1 \\
-0.7\end{array}$ \\
\hline 600 & $<1.2$ & -0.1 & 810 & 1.9 & -1.7 \\
\hline 610 & 5.5 & -5.3 & 820 & 1.3 & -2.0 \\
\hline 620 & 2.0 & -2.7 & 830 & $<1.0$ & \\
\hline 630 & 5.9 & -5.7 & 910 & 2.3 & +2.5 \\
\hline 640 & 5.4 & -3.4 & 920 & 1.2 & $\begin{array}{r}+ \\
+\quad 0.9\end{array}$ \\
\hline 650 & 4.0 & $+\mathbf{3 . 9}$ & 930 & $\mathbf{3 . 3}$ & -4.4 \\
\hline
\end{tabular}

It would seem to be of interest to compare the molecule of phosphorous acid with that of phosphoric acid ${ }^{2}$. In phosphoric acid the short $\mathrm{P}-\mathrm{O}$ bond is found to be $1.52 \AA$ and the $\mathrm{P}-\mathrm{OH}$ bonds to be $1.57 \AA$. Values of $106^{\circ}$ and $112^{\circ}$ were found for the two types of bond angles. Phosphorous acid may be derived from phosphoric acid by substituting a hydroxyl group by a hydrogen atom. It is seen that this change appears to make all the bond angles deviate more from the tetrahedral angle and all the $\mathrm{P}-\mathrm{O}$ bonds shorter, especially the short $\mathrm{P}-\mathrm{O}$ bond. Correspondingly, the angles involving this bond are greater in $\mathrm{H}_{3} \mathrm{PO}_{3}$ than in $\mathrm{H}_{3} \mathrm{PO}_{4}$, and the angles between $\mathrm{P}-\mathrm{OH}$ bonds smaller. Although these differences are small, they are probably significant in view of the agreement in the dimensions of the two independent molecules of $\mathrm{H}_{3} \mathrm{PO}_{3}$.

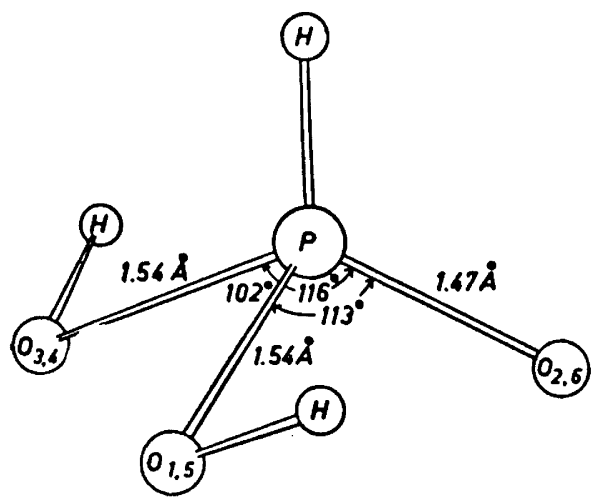

Fig. 3. Bond lengths and bond angles in $\mathrm{H}_{3} \mathrm{PO}_{\mathbf{3}}$. 


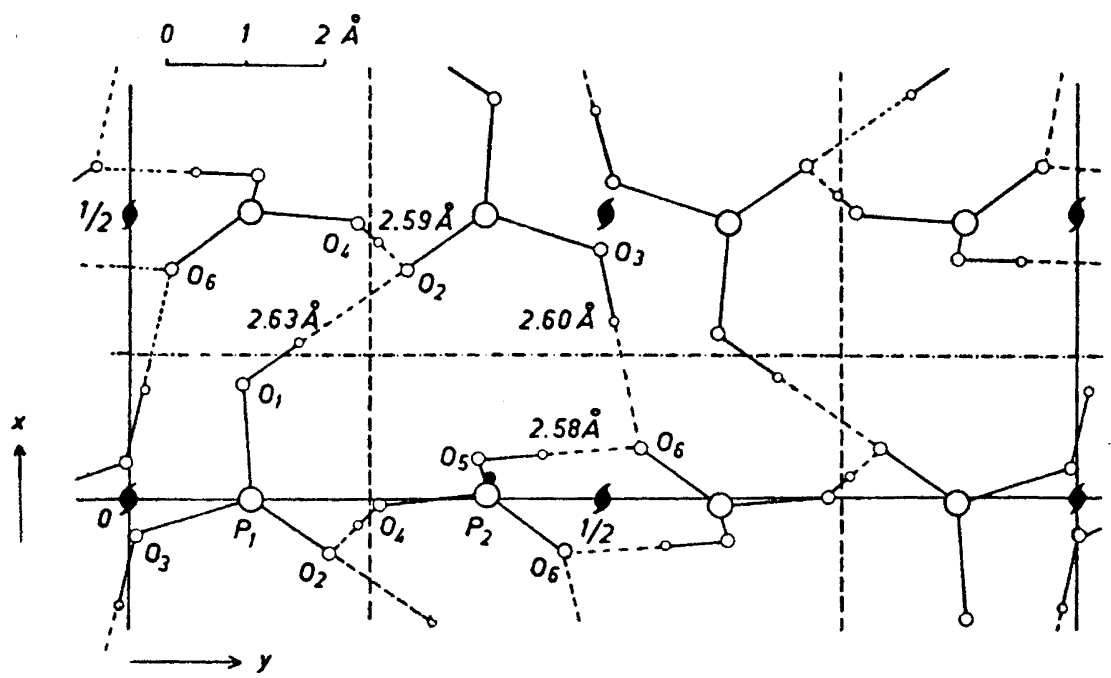

Fig. 4. The $c$ projection of the structure. Broken lines indicate hydrogen bonds.

The molecules are linked together by hydrogen bonds, as shown in Fig. 4. There are two such bonds for each molecule, as to be expected from the formula $\mathrm{HPO}(\mathrm{OH})_{2}$, but not from $\mathrm{P}(\mathrm{OH})_{3}$. The four bonds are of nearly equal length, the values $2.59 \AA, 2.63 \AA, 2.58 \AA$ and $2.60 \AA$ being found. All other intermolecular $\mathrm{O}-\mathrm{O}$ distances are greater than 3.0 $\AA$. The two "lone" oxygen atoms $\mathrm{O}_{2}$ and $\mathrm{O}_{6}$ each take part in two hydrogen bonds, whereas each of the other oxygen atoms is involved in only one such bond. As generally found in crystal structures, the angles between the hydrogen bonds and the $\mathrm{P}-\mathrm{O}$ bonds are least distorted at the oxygen atoms to which the hydrogen atoms are bonded. The two hydrogen bonds to the "lone" oxygen atom in $\mathrm{H}_{3} \mathrm{PO}_{4}$ are $2.53 \AA$ of length, somewhat shorter than in the present case.

The structure has pseudo-tetragonal symmetry, with an approximate $4_{1}$ axis roughly at $(0, y, 1 / 4)$. This holds not only for the atomic coordinates and the molecular dimensions, but also for the hydrogen bonding scheme.

One of us (S.F.) wishes to thank Nansenfondet og de dermed forbundne fond for a grant.

\section{REFERENCES}

1. Corbridge, D. E. C. Acta Cryst. 9 (1956) 991.

2. Furberg, S. Acta Chem. Scand. 9 (1955) 1557.

3. Sayre, D. M. Acta Cryst. 5 (1952) 60.

4. Viervoll, H. and Øgrim, O. Acta Cryst. 2 (1949) 277.

5. Cruickshank, D. W. J. Acta Cryst. 2 (1949) 65.

6. Dunitz, J. D. and Rollett, J. S. Acta Cryst. 9 (1956) 327. 